An investigation into the impact of variations of ambient air pollution and meteorological factors on lung cancer mortality in Yangtze River Delta

Chee Yap Chung, Jie Yang, Jun He, Xiaogang Yang, Richard Hubbard, Dongsheng Ji

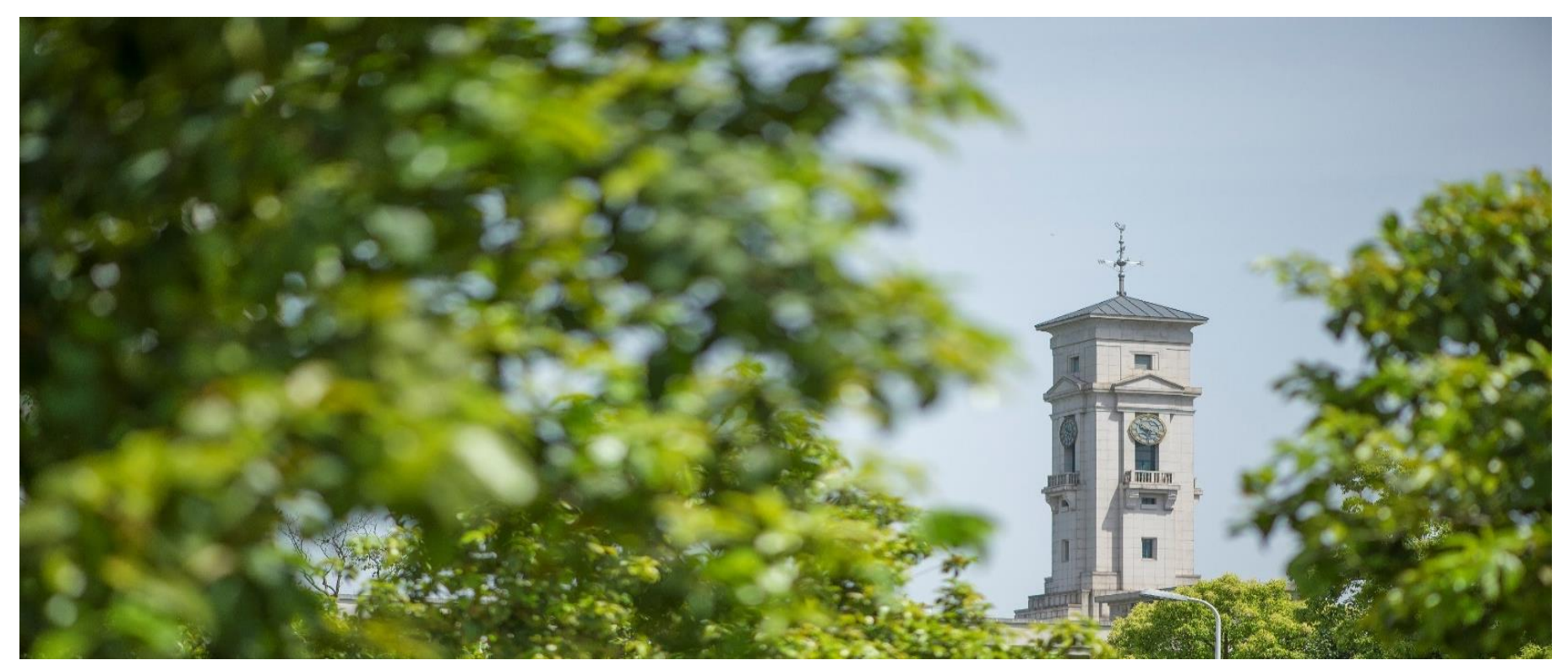


University of Nottingham Ningbo China, 199 Taikang East Road, Ningbo, 315100, Zhejiang, China.

First published 2021

This work is made available under the terms of the Creative Commons Attribution 4.0 International License:

http://creativecommons.org/licenses/by/4.0

The work is licenced to the University of Nottingham Ningbo China under the Global University Publication Licence:

https://www.nottingham.edu.cn/en/library/documents/research/global -university-publications-licence-2.0.pdf 


\section{An investigation into the impact of variations of ambient air pollution and meteorological factors on lung cancer mortality in Yangtze River Delta}

Chee Yap Chung ${ }^{\mathrm{a}}$, Jie Yang ${ }^{\mathrm{b}, \mathrm{f}, *}$, Jun He $\mathrm{He}^{\mathrm{a}}$, Xiaogang Yang ${ }^{\mathrm{c}}$, Richard Hubbard ${ }^{\mathrm{d}}$, Dongsheng Jie

${ }^{\text {aDepartment }}$ of Chemical and Environmental Engineering, University of Nottingham Ningbo China, Ningbo 315100, PR China

bSchool of Mathematical Sciences, University of Nottingham Ningbo China, Ningbo 315100, PR China

'Department of Mechanical, Materials and Manufacturing Engineering, University of Nottingham Ningbo China, Ningbo 315100, PR China

dSchool of Medicine, University of Nottingham, Nottingham NG7 2UH, UK

eState key laboratory of Atmospheric Boundary Layer Physics and Chemistry, Institute of Atmospheric Physics, Chinese Academy of Sciences, Beijing 100191, PR China

\section{Abstract}

Lung cancer (LC) mortality, as one of the top cancer deaths in China, has been associated with increased levels of exposure to ambient air pollutants. In this study, different lag times on weekly basis were applied to study the association of air pollutants (PM2.5, PM10, and NO2) and LC mortality in Ningbo, and in subpopulations at different age groups and genders. Furthermore, seasonal variations of pollutant concentrations and meteorological variables (temperature, relative humidity, and wind speed) were analysed. A generalised additive model (GAM) using Poisson regression was employed to estimate the effect of single pollutant model on LC mortality in Yangtze River Delta using Ningbo as a case study. It was reported that there were statistically significant relationships between lung cancer mortality and air pollutants. Increases of $6.2 \%$ (95\% 
confidence interval [Cl]: $0.2 \%$ to $12.6 \%)$ and $4.3 \%(95 \% \mathrm{Cl}: 0.1 \%$ to $8.5 \%)$ weekly total LC mortality with a 3-week lag time were linked to each $10 \mu \mathrm{g} / \mathrm{m}^{3}$ increase of weekly average $\mathrm{PM}_{2.5}$ and $\mathrm{PM}_{10}$ respectively. The association of air pollutants $\left(\mathrm{PM}_{2.5}, \mathrm{PM}_{10}\right.$ and $\left.\mathrm{NO}_{2}\right)$ and $\mathrm{LC}$ mortality with a 3-week lag time was also found statistically significant during periods of low temperature $\left(T<18^{\circ} \mathrm{C}\right)$, low relative humidity $(H<73.7 \%)$ and low wind speed $(u<2.8 \mathrm{~m} / \mathrm{s})$, respectively. The female population was found to be more susceptible to the exposure to air pollution than the male population. In addition, the population with an age of 50 years or above was shown to be more sensitive to ambient air pollutant. These outcomes indicated that increased risk of lung cancer mortality was evidently linked to exposure to ambient air pollutant on a weekly basis. The impact of weekly variation on the LC mortality and air pollutant levels should be considered in air pollution-related health burden analysis.

\section{Keywords}

Ambient air pollution; Lag time; Lung cancer mortality; Meteorological factors; Modelling; Yangtze River Delta

${ }^{*}$ Corresponding author: Email address: Jie.Yang@hull.ac.uk (Yang J.) fPresent address: Department of Physics \& Mathematics, University of Hull, Hull, HU6 7RX, UK

\section{Introduction}

Lung cancer (LC) is characterised by the uncontrolled growth of abnormal cells in the lungs, which may eventually spread to the other organs by a process known as metastasis (Tanoue, 2012). An increase in the risk factor of most LC cases has been shown to be associated with increased levels of tobacco smoking. However, an increased risk of LC has also been associated with exposure to ambient air pollution (Alberg and Samet, 2003). Carcinogens, which 
are generated from processes such as industrial combustion and vehicle exhaust, are often transported along with fine particulate matter and dispersed over the environment. These carcinogens are potentially responsible for the increased risk of lung cancer in an urban area with a high population density (Pope et al., 2011; Alberg and Samet, 2003).

According to the Global Burden of Cancer, LC is the top leading cause for cancer mortality in China (Fitzmaurice et al., 2017). As China experiences rapid economic growth over the past few decades, the level of energy consumption, industrial waste, motor vehicle usage and urban development have all increased, which then contribute towards a dramatic increase in ambient air pollution levels. Furthermore, the significant increase of population also requires a higher level of energy consumption where coal is still one of the primary sources of energy utilised by many industries and households. These factors have all contributed towards exacerbating the effects of local air pollution and carbon emission in China (Chen and Xu, 2010).

Ambient particulate matter (PM) pollution, which was ranked as the fifth-leading risk factor for disease burden in China, was also the top leading environmental risk factor for the country in 2015 (Forouzanfar et al., 2016). PM is a complex heterogeneous mixture of solid and liquid particles suspended in the air, varying from a few $\mathrm{nm}$ to tens of $\mu \mathrm{m}$ in size (Jin et al., 2016). Sources of PM can be identified as primary emission or secondary formation processes resulting from power plant, oil refineries, residential fuel combustion and construction (Jin et al., 2016). Airborne PM has received a lot of attention in the last few decades as they pose a significant risk to human health. For instance, $\mathrm{PM}_{10}$ with an aerodynamic diameter of less than $10 \mu \mathrm{m}$ can enter the lower respiratory system. $\mathrm{PM}_{2.5}$, which is smaller than $2.5 \mu \mathrm{m}$ in aerodynamic diameter, has gradually received increased attention and awareness as it can penetrate into the gas-exchange area of the lung (Brunekreef and Holgate, 2002). In 2012, $\mathrm{PM}_{2.5}$ was added into the Chinese 
National Ambient Air Quality Standards (NAAQS) as a new criterion pollutant in order to monitor air quality control in China (Chen et al., 2015; You, 2014).

The association of exposure to ambient PM pollution with respiratory and cardiovascular diseases such as stroke, ischaemic heart disease (IHD), chronic obstructive pulmonary disease (COPD) and LC has been well analysed in previous studies (Forouzanfar et al., 2016; Yang et al., 2013; Burnett et al., 2014). However, previous studies on the association between LC mortality and exposure to ambient air pollution have been limited and results have been inconsistent. For example, it analysed the positive relationship between the current-day concentration of $\mathrm{PM}_{2.5}$ pollutant and LC mortality in Chinese cities including Beijing, Chongqing and Guangzhou (Wang et al., 2019). However, another study conducted in Hebei demonstrated that there was no statistically significant association between LC mortality and $\mathrm{PM}_{10}$ (Zhu et al., 2019a). Currently, little is known about the effect of seasonal variation and lag time on the LC mortality attributable to ambient air pollution. The effects of $\mathrm{SO}_{2}, \mathrm{NO}_{2}$ and $\mathrm{PM}_{10}$ on mortality linked to respiratory diseases mortality were previously found to be strongest at lag times of 1 day, 1 day and 2 days, respectively, using the single-day lag model (Zhu et al., 2019a). Seasonality can also impact the acute effects of ambient PM on mortality (Chen et al., 2013). The mortality attributable to $\mathrm{PM}_{10}$ was found at its highest level in winter and lowest in summer (Peng et al., 2005). Previous studies have also demonstrated that exposure to $\mathrm{NO}_{2}$ is linked to an increase in the risk of respiratory mortality or morbidity including respiratory inflammation and lung function impairment (Jiang et al., 2019).

The meteorological variables such as temperature, relative humidity, and wind speed play a significant role when defining the association between air pollutant and disease burden. Previous study conducted in Tianjian pointed out a U-shaped relationship between temperature and mortality, which suggested that both extreme low and high ambient temperature increased 
the risk of mortality (Guo et al., 2011). PM concentration was shown to be negatively and nonlinearly associated with wind speed ( $\mathrm{Li}$ et al., 2015). Moreover, temperature and relative humidity are often considered as potential confounding factors which need to be adjusted in the stage of model development (Oo et al., 2020; Quu et al., 2018; Zhu et al., 2019b). Therefore, the effect of meteorological factors (temperature, relative humidity, and wind speed) was added and adjusted in the model development of this study to obtain a more accurate relationship between air pollutant and LC mortality.

Since previous studies on the relationship between LC mortality and PM have been shown to be inconsistent, further investigation is required on the effect of lag time and variation of meteorological conditions on LC mortality attributable to air pollution. Furthermore, most of the previous studies studied the association between LC mortality and air pollutant using lag time effect in a daily basis, which did not consider the potential accumulative effect of air pollutant on LC mortality on a weekly basis. In order to better capture the significant effect of the air pollutant, a new perspective with the different lag time basis is needed to explore when addressing the association between air pollutant and disease burden. Therefore, in this study, the association between air pollutant and LC mortality is characterised on a weekly basis with the consideration of lag time and meteorological changes. Ningbo, a port city located in the Yangtze River Delta region, is employed as a case study with a focus on available pollutant, meteorological and mortality data collected in 2015 . The objectives of this study are to determine (1) the association of air pollutants and LC mortality with different lag times on weekly basis; (2) the seasonal variations of air pollutants, meteorological variables (temperature, humidity and wind speed) and LC mortality; and (3) the trends of LC mortality in a subpopulation according to the stratification of age groups and gender. 


\section{Methodology}

\subsection{Study area}

Located in the southeast region of the Yangtze River Delta (YRD), Ningbo is a coastal city of Zhejiang province that currently consists of six districts, two county-level cities and two counties. Ningbo has four distinct seasons and its climate is mostly affected by subtropical monsoons. The annual average temperature of the city is reported as 16.9 degrees Celsius with the highest monthly average temperature of $28.3^{\circ} \mathrm{C}$ in July and lowest monthly average temperature of $5.3^{\circ} \mathrm{C}$ in January. In 2015, the total number of registered people in Ningbo was approximately 5.86 million with $64.6 \%$ of them accounting for the urban population. With a total land area of 9816 $\mathrm{km}^{2}$, Ningbo had an overall population density of 598 people $/ \mathrm{km}^{2}$ and a population density of 943 person $/ \mathrm{km}^{2}$ in its urban districts (Ningbo Statistical Yearbook 2016).

After the open-door policy was announced by the central government in 1979, the manufacturing industries in Ningbo have grown dramatically due to its ideal geographical location of being a port city, which has contributed to its economic development. This has resulted in significant industrialisation and urbanisation taking place in Ningbo (Tang et al., 2015). By the end of 2015, the total GDP in Ningbo accounted for 801.15 billion RMB with $3.6 \%, 49.0 \%$ and $47.4 \%$ of the total GDP contributed by the primary, secondary and tertiary industries, respectively (Ningbo Statistical Yearbook 2016). As a result of rapid industrialisation, Ningbo is experiencing increased levels of respiratory related diseases such as lung cancer. In order to carry out a comprehensive study of the relationship between ambient air pollution and LC mortality, Ningbo was chosen as a case study. 


\subsection{Data collection and handling}

Daily LC mortality data of residents living in Ningbo was collected from Ningbo Centre for Disease Control and Prevention (Ningbo CDC) during the year of 2015. The mortality attributable to lung cancer was classified as C33 (malignant neoplasm of trachea) and C34 (malignant neoplasm of bronchus and lung) according to the International Classification of Diseases, Revision 10 (ICD 10). The daily LC mortality derived from the raw data was used to calculate the total number of LC mortality on weekly basis for the study.

Both air pollutant concentration data and meteorological data in an hourly average basis during the year of 2015 were obtained from the Ningbo Environmental Monitoring Centre (Ningbo EMC). Two monitoring stations, which were Ningbo Taigu primary school $\left(29^{\circ} 860728^{\prime} \mathrm{N}, 121^{\circ}\right.$ 289801' E) and Sanjiang middle school (29 $\left.887798^{\prime} \mathrm{N}, 1^{\circ} 1^{\circ} 558176^{\prime} \mathrm{E}\right)$, were selected to represent the air pollutant concentration and meteorological data of Ningbo. As the location of two monitoring stations are near to town centre, which is surrounded by commercial activities and residential areas, the pollutant data is acceptable to describe exposures to air pollutants in Ningbo city. The daily average and weekly average values of both air pollutant concentration and meteorological data were derived from raw data collected for further analysis.

In addition, the weekly average values of air pollutant concentration were measured based on the requirement of the Chinese Ambient Air Quality Standard (GB3095-2012), which validates the effectiveness of air pollutant data, using the following criteria: (1) Hourly average concentrations which were a negative value or equal to zero, or entries lacking comprehensive data were eliminated; (2) Each day must have 20 hours or more hourly average concentration data available; (3) Each month must have at least 27 days or more daily average concentration 
data available (at least 25 days or more daily average concentration data must be available in February); (4) 324 days or more daily average concentration data must be available per year.

\subsection{Statistical analysis and modelling}

The demographic characteristics of the study population were derived during the data collection process. Key pollutants which exceeded the minimum concentration that may pose a health risk to the public were selected by following the standard of the Ambient Air Quality Index (AQI). Furthermore, a study of Pearson's correlation between the air pollutants was conducted in order to determine their collinearity. A time-series single pollutant model was studied by fitting the generalised additive model (GAM) with Poisson regression as shown in equation (1),

$$
\ln \left[E\left(m_{i j}\right)\right]=\alpha+\beta z_{j}+n s(u, d f)+n s(T, d f)+n s(H, d f)+n s(w, d f)
$$

where $z_{j}$ is the weekly average concentration of pollutant $j ; E\left(m_{i j}\right)$ is the expected number of weekly total LC mortality with respect to pollutant $j$ and lag time $i=0,1,2,3,4$ week; $\alpha$ is the model intercept; $\beta$ is the corresponding regression coefficient; $u, T, H$ are the weekly average values of wind speed, temperature and relative humidity, respectively; $w$ is the sequential number of week in the study year. The function $n s$ ( ) represents natural spline function in the regression model, which was used to control the potential confounding factors such as meteorological variable and time effect. $d f$ is degree of freedom, and different values for $u, T, H$ and $w$ are set

to $5,9,5$ and 6 , respectively. With the smoothing term in the model fitting, the analyses are adjusted for wind speed, temperature, relative humidity and the effect of week. 
For the model fitting, the association of the weekly average pollutant concentration and total number of LC mortality on a weekly basis was examined over the study period of 2015 in the Ningbo city. An odd ratio and 95\% confidence intervals of LC mortality with different lag times attributable to each $10 \mu \mathrm{g} / \mathrm{m}^{3}$ increase in the single pollutant model were examined and compared. Furthermore, the performance of models with different lag times were examined by comparing the root mean square error (RMSE) and Akaike information criterion (AIC). The final model for each pollutant was determined based on the minimum RMSE and AIC, and it was then used for further analysis. The sensitivity analyses were conducted in order to test the robustness of the result by altering the $d f$ for wind speed, temperature, relative humidity and week from 4 to 6,8 to 10,4 to 6 and 5 to 7 , respectively.

For the seasonal analyses, the data was stratified into four distinct seasons: winter (from December to February; week 1 to 9), spring (from March to May; week 10 to 22), summer (from June to August; week 23 to 35 ) and autumn (from September to November; week 36 to 48). The effect of meteorological variables such as $u, T$, and $H$ on the behaviour of LC mortality with respect to different lag times were also studied in the following analysis. Daily average values of meteorological variables were employed as the standard value to categorise the data into two different groups (high $u, T, H$ and low $u, T, H$ ) for discussion purposes. For the stratification analyses, the effect of air pollutant on LC mortality was studied in different subpopulations by gender (male and female) and age (under 50, between 50 and 65, and over 65 years old, respectively). All the analyses were conducted using the mixed GAM computation vehicle (mgcv) and splines packages in $\mathrm{R}$ statistical software (version 3.6.1). The result was considered as statistically significant when the measured $p$-value was less than $0.05(P<0.05)$. 


\section{Results}

\subsection{Description of the study objects and population exposure}

During the study period from 1st January 2015 to 31 st December 2015, a total number of 3406 lung cancer (LC) deaths was recorded in the Ningbo, including 2474 deaths (72.6\%) from male patients and 932 deaths (27.4\%) from female patients. The stratification of LC mortality according to gender and age group is shown in Table 1. By the end of 2015, the total deaths and the deaths due to malignant tumour in Ningbo were recorded as 37838 and 12344 cases, respectively. As a result, $9.0 \%$ of death population and $27.6 \%$ of deaths due to malignant tumour in Ningbo were associated with lung cancer mortality during the study period.

Table 1. Demographic characteristics of the study population.

\begin{tabular}{c|c|cc}
\hline Characteristics & Total & Male & Female \\
\hline Total population & 5865731 & $2915471(49.7 \%)$ & $2950260(50.3 \%)$ \\
Death population & 37838 & $21225(56.1 \%)$ & $16613(43.9 \%)$ \\
Deaths due to malignant tumour & 12344 & $8219(66.6 \%)$ & $4125(33.4 \%)$ \\
Lung cancer mortality & 3406 & $2474(72.6 \%)$ & $932(27.4 \%)$ \\
Age of death (<50) & $135(4.0 \%)$ & $91(67.4 \%)$ & $44(32.6 \%)$ \\
Age of death (50-69) & $1520(44.6 \%)$ & $1125(74.0 \%)$ & $395(26.0 \%)$ \\
Age of death (>69) & $1751(51.4 \%)$ & $1258(71.8 \%)$ & $493(28.2 \%)$ \\
\hline
\end{tabular}

In Table 2, the standard concentrations which contribute towards an individual ambient quality index (IAQI) value of 50 were based on the Technical Regulation in the Ambient Air Quality Index (HJ 633-2012). All pollutant concentrations were reported as the 24-hour average value, except for $\mathrm{O}_{3}$ which is recorded as the average value per hour. Among the air pollutants, the daily 
average concentration of air pollutants $\mathrm{PM}_{2.5}, \mathrm{PM}_{10}$ and $\mathrm{NO}_{2}$ exceeded the concentration, which contributes to the IAQI value of 50 , as shown in Table 2. An IAQI value of 50 is the minimum threshold of a potential risk of air pollutant to public health, as indicated in "Standard" column of Table 2. Therefore, $\mathrm{PM}_{2.5}, \mathrm{PM}_{10}$ and $\mathrm{NO}_{2}$ were then selected for further investigation on the association with lung cancer mortality using the single pollutant model. Wind speed, temperature and relative humidity had daily mean values of $2.8 \mathrm{~m} / \mathrm{s}, 18.0^{\circ} \mathrm{C}$ and $73.7 \%$ recorded, respectively. These mean values were used as the cut-offs for dividing the data into high and low levels of meteorological conditions in the stratification analyses. Furthermore, the daily average number of LC mortality was recorded as 9.3, with the highest daily LC mortality value recorded of 20 .

Table 2. Daily average air pollutant concentration data and meteorological data in Ningbo.

\begin{tabular}{|c|c|c|c|c|c|c|c|c|}
\hline Variables & Mean & SD & Standard & Min & $\begin{array}{l}\text { Lower } \\
\text { quartile }\end{array}$ & Median & $\begin{array}{l}\text { Upper } \\
\text { quartile }\end{array}$ & Max \\
\hline $\mathrm{PM}_{2.5}\left(\mu \mathrm{g} / \mathrm{m}^{3}\right)$ & 44.8 & 25.3 & 35.0 & 2.4 & 26.8 & 38.6 & 55.3 & 153.0 \\
\hline $\mathrm{PM}_{10}\left(\mu \mathrm{g} / \mathrm{m}^{3}\right)$ & 69.1 & 36.1 & 50.0 & 4.1 & 41.9 & 61.2 & 86.3 & 231.0 \\
\hline $\mathrm{CO}\left(\mathrm{mg} / \mathrm{m}^{3}\right)$ & 0.9 & 0.3 & 2.0 & 0.4 & 0.7 & 0.8 & 1.0 & 1.9 \\
\hline $\mathrm{NO}_{2}\left(\mu \mathrm{g} / \mathrm{m}^{3}\right)$ & 45.0 & 17.3 & 40.0 & 11.6 & 31.6 & 42.6 & 57.1 & 109.0 \\
\hline $\mathrm{SO}_{2}\left(\mu \mathrm{g} / \mathrm{m}^{3}\right)$ & 18.1 & 7.6 & 50.0 & 6.4 & 13.3 & 16.8 & 21.0 & 68.0 \\
\hline $\mathrm{O}_{3}\left(\mu \mathrm{g} / \mathrm{m}^{3}\right)$ & 63.4 & 28.3 & 160.0 & 4.2 & 42.2 & 63.6 & 81.7 & 169.4 \\
\hline $\mathbf{u}(\mathrm{m} / \mathrm{s})$ & 2.8 & 1.1 & - & 0.5 & 2.1 & 2.7 & 3.4 & 6.6 \\
\hline $\mathrm{T}\left({ }^{\circ} \mathrm{C}\right)$ & 18.0 & 7.9 & - & 2.1 & 10.7 & 19.6 & 24.1 & 33.0 \\
\hline $\mathbf{H}(\%)$ & 73.7 & 13.3 & - & 34.7 & 64.4 & 74.1 & 85.1 & 100.0 \\
\hline LC mortality & 9.3 & 3.0 & - & 1.0 & 7.0 & 9.0 & 11.0 & 20.0 \\
\hline
\end{tabular}




\subsection{Pearson's correlation coefficient}

Pearson's correlation coefficient between the pollutants was measured in order to investigate their collinearity in the study, as shown in Table 3. The result showed that all the pollutants are highly correlated to each other with a positive relationship, except for $\mathrm{O}_{3}$. Table 3 also indicates that the collinearities among all the pollutants are likely to exist, which will affect the accuracy of result for a multiple regression model. Therefore, the effect of single pollutant model on LC mortality was investigated in this study. Furthermore, it was found that all the pollutants except $\mathrm{O}_{3}$ were negatively associated with meteorological variables such as temperature $(T)$, relative humidity $(H)$ and wind speed $(u)$. This implies that the occurrence of higher pollutant concentrations is likely related to the meteorological conditions of lower temperature, lower relative humidity and lower wind speed.

Table 3. Pearson's correlation coefficient between air pollutants and meteorological variables.

\begin{tabular}{|c|c|c|c|c|c|c|c|c|}
\hline & $\mathrm{PM}_{10}$ & CO & $\mathrm{NO}_{2}$ & $\mathrm{SO}_{2}$ & $\mathrm{O}_{3}$ & $T$ & $H$ & $u$ \\
\hline$\overline{\mathrm{PM}_{2.5}}$ & 0.972 & 0.783 & 0.767 & 0.750 & -0.465 & -0.682 & -0.422 & -0.258 \\
\hline $\mathrm{PM}_{10}$ & & 0.710 & 0.796 & 0.798 & -0.410 & -0.644 & -0.479 & -0.306 \\
\hline co & & & 0.746 & 0.560 & -0.551 & -0.478 & -0.176 & -0.065 \\
\hline $\mathrm{NO}_{2}$ & & & & 0.729 & -0.580 & -0.622 & -0.271 & -0.103 \\
\hline $\mathrm{SO}_{2}$ & & & & & -0.335 & -0.358 & -0.429 & -0.291 \\
\hline $\mathrm{O}_{3}$ & & & & & & 0.640 & -0.065 & 0.115 \\
\hline$T$ & & & & & & & 0.355 & 0.152 \\
\hline$H$ & & & & & & & & 0.534 \\
\hline
\end{tabular}




\subsection{Association of air pollutants $\left(\mathrm{PM}_{2.5}, \mathrm{PM}_{10}\right.$ and $\left.\mathrm{NO}_{2}\right)$ and LC mortality with different lag times}

Table 4 shows the association of each $10 \mu \mathrm{g} / \mathrm{m}^{3}$ increase of pollutant concentration with LC mortality with different lag times. With the minimum AIC and residual errors, the single pollutant model with a 3-week lag time was found to be best model for predicting the weekly total LC mortality from the weekly average pollutant concentration $\left(\mathrm{PM}_{2.5}\right.$ and $\left.\mathrm{PM}_{10}\right)$ as compared to the models with other lag times. The result of each model performance (AIC and RMSE) was displayed in Supplemental Material (Table S1). An increase of $6.2 \%(95 \% \mathrm{Cl}: 0.2 \%$ to $12.6 \%)$ weekly total LC mortality with a 3-week lag time was associated with an increase of $10 \mu \mathrm{g} / \mathrm{m}^{3}$ weekly average $\mathrm{PM}_{2.5}$. In addition, the estimated increase of $4.3 \%(95 \% \mathrm{Cl}: 0.1 \%$ to $8.5 \%)$ weekly total LC mortality with a 3-week lag time was observed by increasing $10 \mu \mathrm{g} / \mathrm{m}^{3}$ weekly average values of $\mathrm{PM}_{10}$. For the 3-week lag time, the $\mathrm{p}$-values of the single pollutant model for $\mathrm{PM}_{2.5}$ and $\mathrm{PM}_{10}$ were found to be less than 0.05 , which were considered as statistically significant outcome. The detail p-values of the model fitting were reported in Supplemental Material (Table S2-S4). The result showed there were almost no statistically significant associations between air pollutants $\left(\mathrm{PM}_{2.5}, \mathrm{PM}_{10}\right.$ and $\left.\mathrm{NO}_{2}\right)$ and $\mathrm{LC}$ mortality with the lag times other than 3 weeks. Furthermore, the sensitivity analyses also showed the change of degree of freedom $(d f)$ of key parameters such as temperature, relative humidity, wind speed, and week in the model did not significantly affect the result of the association between LC mortality and pollutant concentration. The result of sensitivity analyses was displayed in Supplemental Material (Table S5-S8). As a result, the effects of air pollutant concentration on LC mortality with a 3-week lag time were investigated further in this study. 
Table 4. Odd ratios (and $95 \mathrm{Cls}$ ) of lung cancer (LC) mortality with different lag weeks, with respect to each $10 \mu \mathrm{g} / \mathrm{m}^{3}$ increase in the single pollutant model in Ningbo. $\left({ }^{*} \mathrm{P}<0.05\right)$

\begin{tabular}{c|c|c|c}
\hline $\begin{array}{c}\text { LC mortality } \\
\text { with lag time }\end{array}$ & $\mathbf{P M}_{2.5}$ & $\mathbf{P M}_{10}$ & NO $_{2}$ \\
\hline No lag time & $0.966(0.913-1.022)$ & $0.975(0.938-1.013)$ & $0.996(0.939-1.058)$ \\
1 week & $1.027(0.971-1.087)$ & $1.014(0.975-1.054)$ & $1.002(0.944-1.064)$ \\
2 weeks & $0.939(0.887-0.993) *$ & $0.962(0.925-1.000) *$ & $0.951(0.895-1.010)$ \\
3 weeks & $1.062(1.002-1.126) *$ & $1.043(1.001-1.085) *$ & $1.046(0.985-1.112)$ \\
4 weeks & $1.026(0.970-1.086)$ & $1.015(0.976-1.055)$ & $1.024(0.965-1.088)$ \\
\hline
\end{tabular}

Figure 1(a) illustrates the association of the weekly average of $\mathrm{PM}_{2.5}$ and the weekly total LC mortality cases with a 3-week lag time. Similar trends were observed over time on both $\mathrm{PM}_{2.5}$ concentration and LC mortality with a 3-week lag time, especially for the beginning section of each peak. The patterns for air pollutants $\mathrm{PM}_{2.5}, \mathrm{PM}_{10}$ and $\mathrm{NO}_{2}$ were also similar to that of $\mathrm{LC}$ mortality over the period of study, as shown in Figure 1Figure 2(a)-(c). The total number of lung cancer mortality cases on a weekly basis remained in the range of 45 to 83 cases per week. However, it was noted that the trends of both air pollutant and LC mortality during the period from week 34 to week 46 were almost identical but slightly shifted, which may suggest the effect of a different lag time during that particular period, as well as the effect of meteorological variables on the association of air pollutants and LC mortality. 
(a)

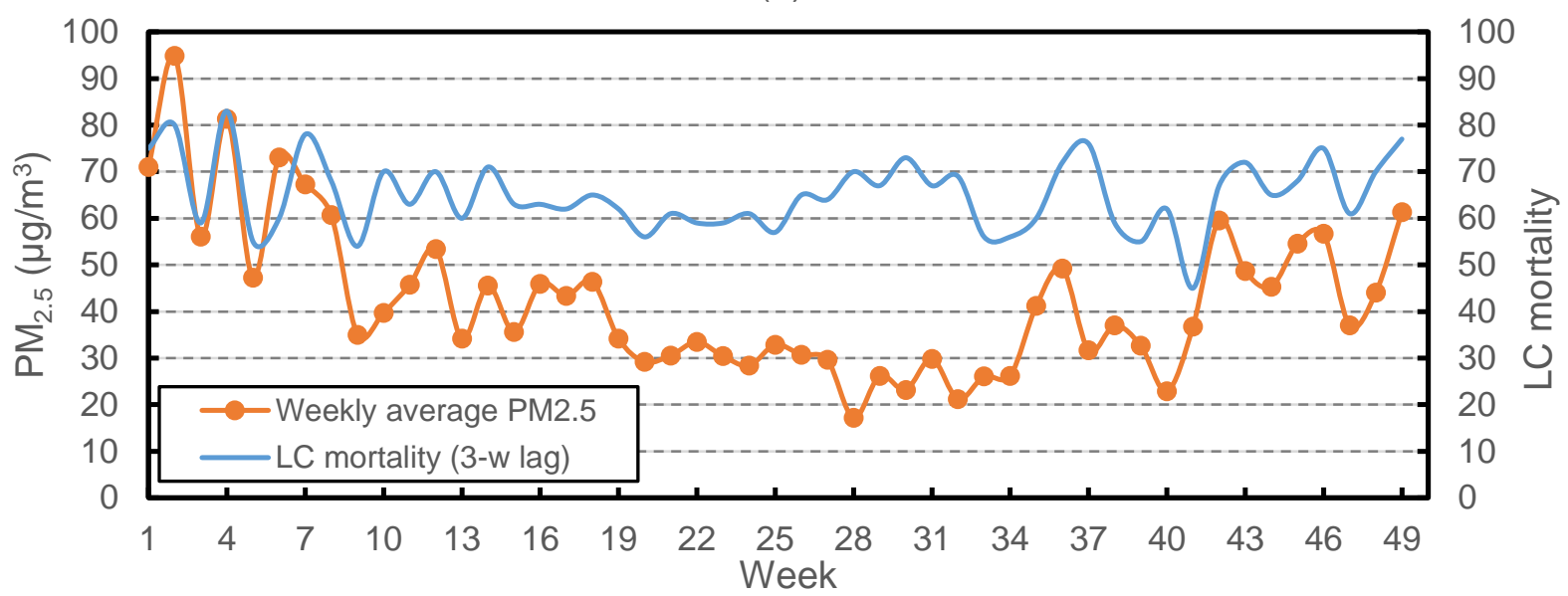

(b)

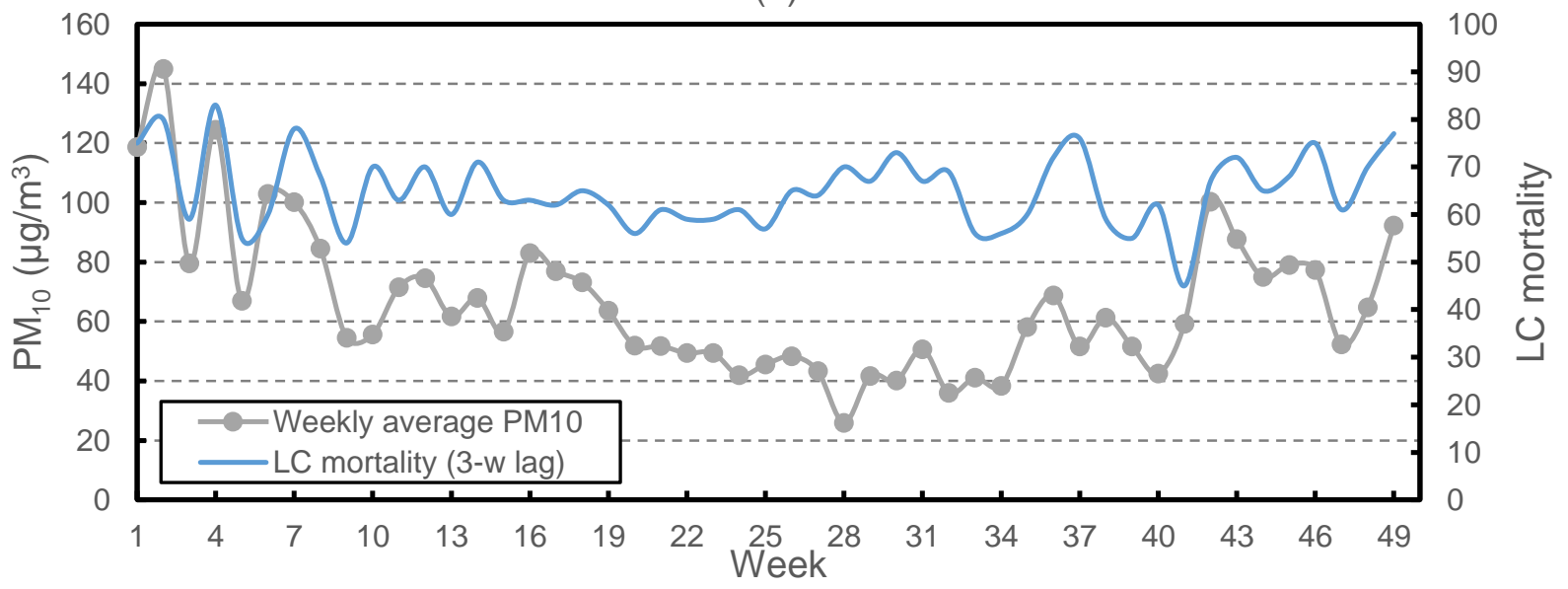

(c)

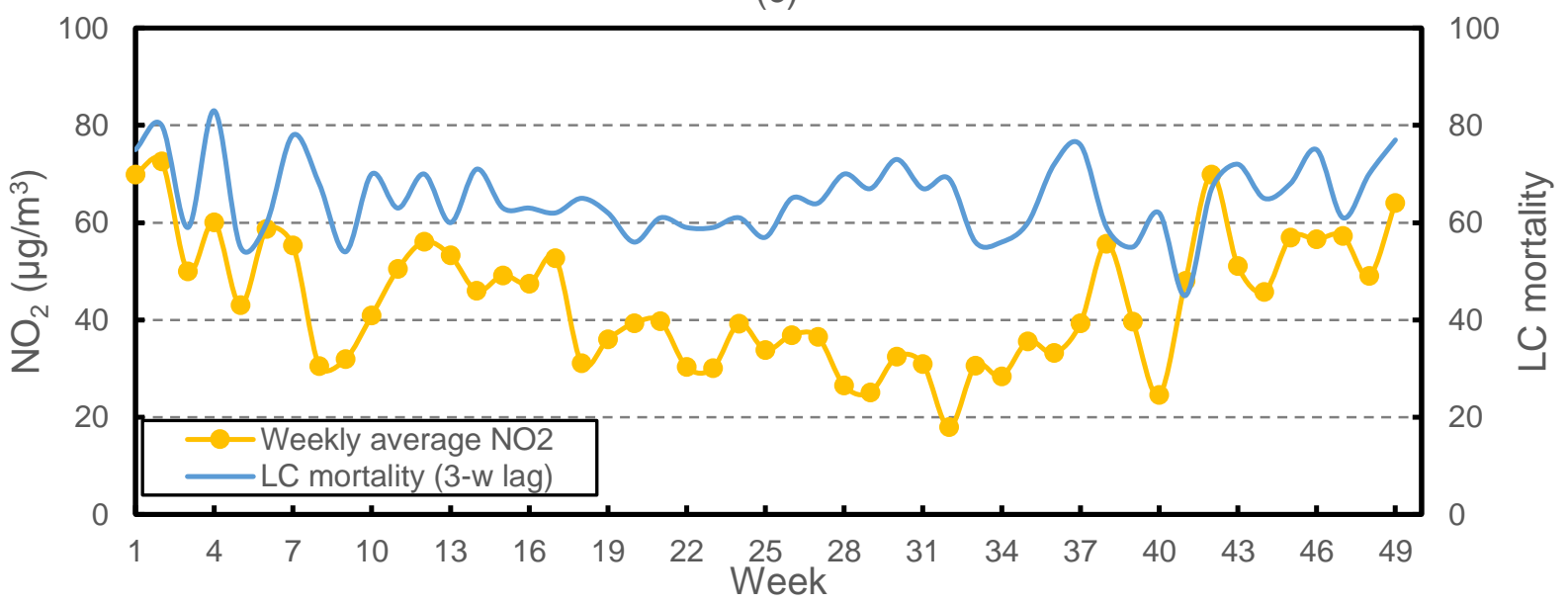

Figure 1. Associations of pollutant concentration (a) $\mathrm{PM}_{2.5}$, (b) $\mathrm{PM}_{10}$, (c) $\mathrm{NO}_{2}$ and LC mortality with a 3-week lag time. 


\subsection{Seasonal variations of air pollutants $\left(\mathrm{PM}_{2.5}, \mathrm{PM}_{10}\right.$ and $\left.\mathrm{NO}_{2}\right)$, meteorological variables (temperature, humidity and wind speed) and LC mortality}

Based on Figure 2(a)-(c), it was observed that the concentrations of air pollutants in winter were much higher and fluctuated more than any other seasons. For example, $\mathrm{PM}_{10}$ reached a high average concentration of over $97.4 \mu \mathrm{g} / \mathrm{m}^{3}$ and the highest weekly concentration of 145.0 $\mu \mathrm{g} / \mathrm{m}^{3}$ occurred in winter. The concentrations of air pollutants were relatively lower and fluctuated less in summer. The average concentrations of $\mathrm{PM}_{2.5}, \mathrm{PM}_{10}$ and $\mathrm{NO}_{2}$ during summer were 27.9 $\mu \mathrm{g} / \mathrm{m}^{3}, 43.1 \mu \mathrm{g} / \mathrm{m}^{3}$ and $31.1 \mu \mathrm{g} / \mathrm{m}^{3}$ respectively, and the values did not exceed the individual standard concentrations contributing to an IAQI value of more than 50. Moreover, it was detected that the pollutant concentrations in both spring and autumn were moderate and closer to their annual average values. The seasonal variation of meteorological variables was notable in this study. Based on Figure 2(g)-(i), temperature, relative humidity and wind speed in Ningbo were at their lowest levels during winter and highest levels during summer, which provides further evidence on their negative correlation with air pollutants $\left(\mathrm{PM}_{2.5}, \mathrm{PM}_{10}\right.$ and $\left.\mathrm{NO}_{2}\right)$.

Figure 2(j) illustrates the seasonal profile of LC mortality in Ningbo. It shows that lower numbers of LC mortality were recorded in summer and autumn, however higher numbers were recorded in winter. In addition, it was noted that there was a strong oscillating effect on the LC mortality in winter, as well as on the concentration of air pollutants over the same period, as shown in both Figure 1 and Figure 2(j). The similar oscillating effects might explain the significant association between air pollutants and LC mortality with a 3-week lag time. 
(a) $\mathrm{PM}_{2.5}$ concentration

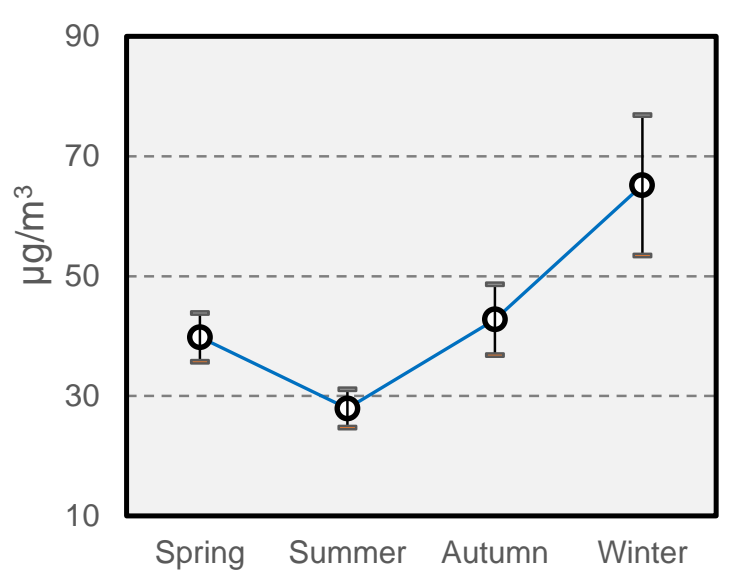

(c) $\mathrm{NO}_{2}$ concentration

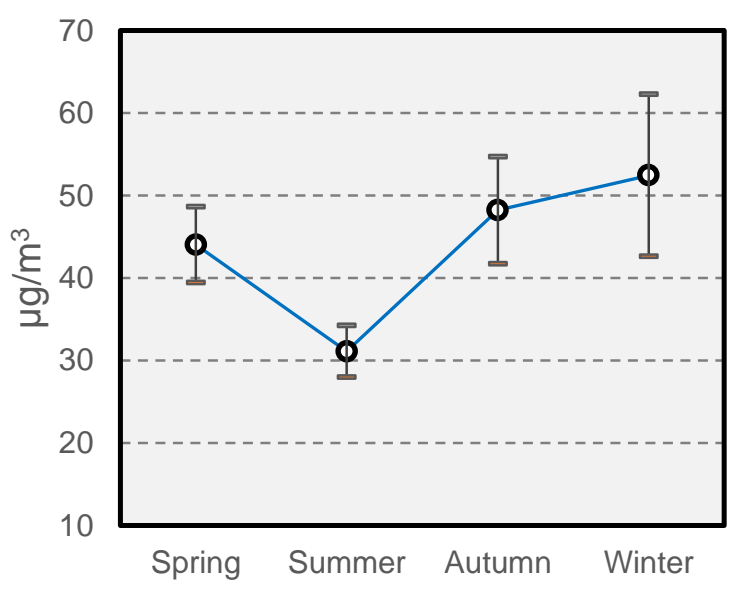

(e) $\mathrm{SO}_{2}$ concentration

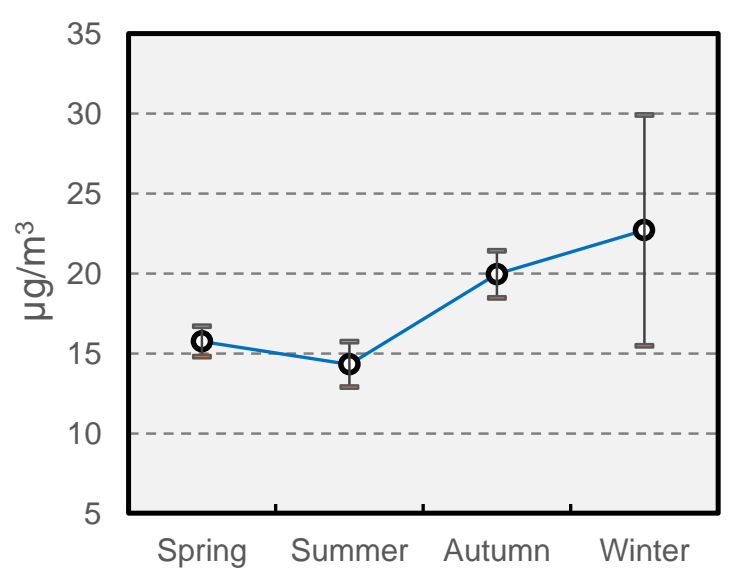

(b) $\mathrm{PM}_{10}$ concentration

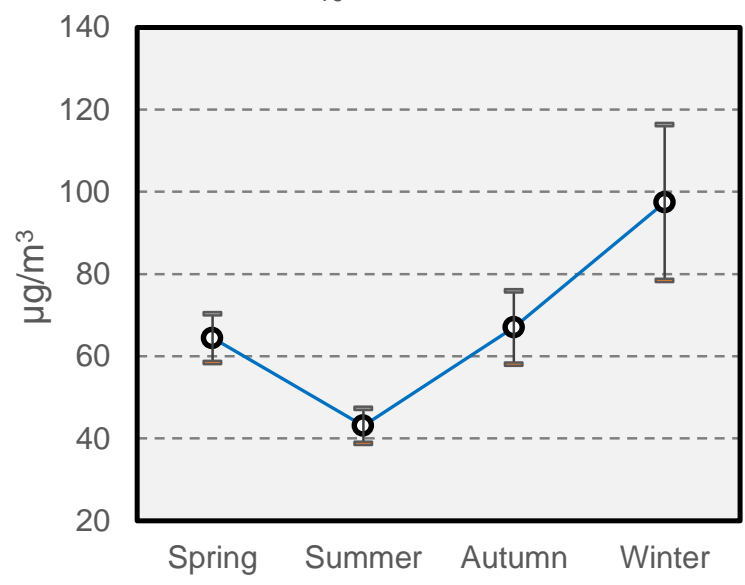

(d) CO concentration

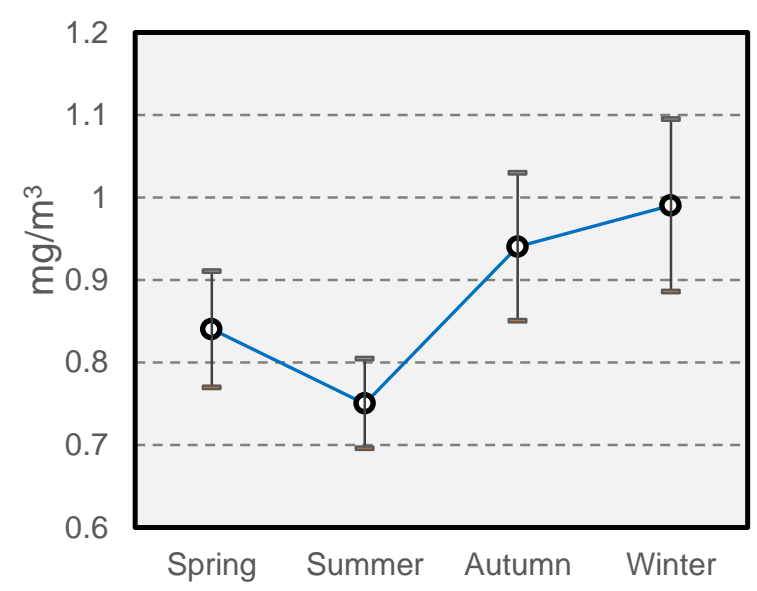

(f) $\mathrm{O}_{3}$ concentration

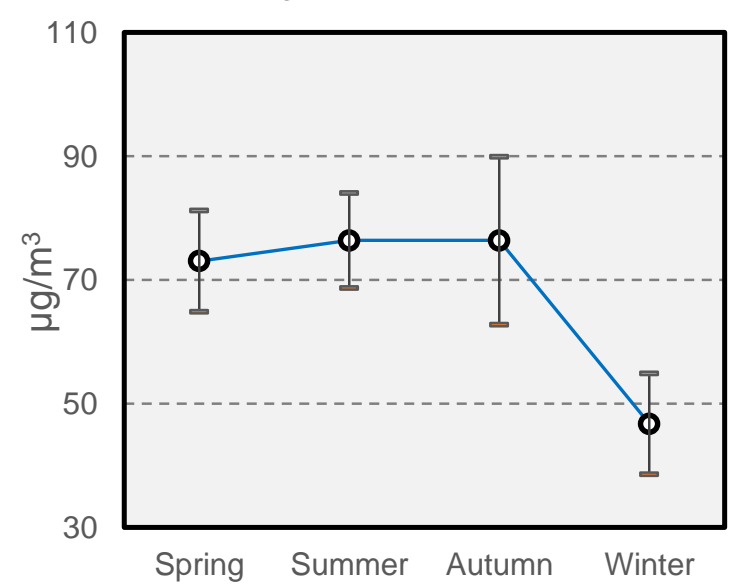


(g) Temperature (T)

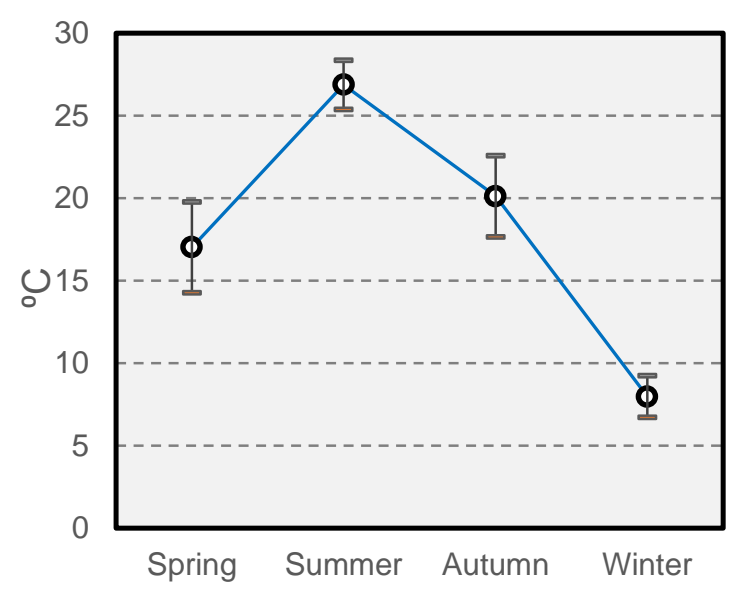

(i) Wind speed (u)

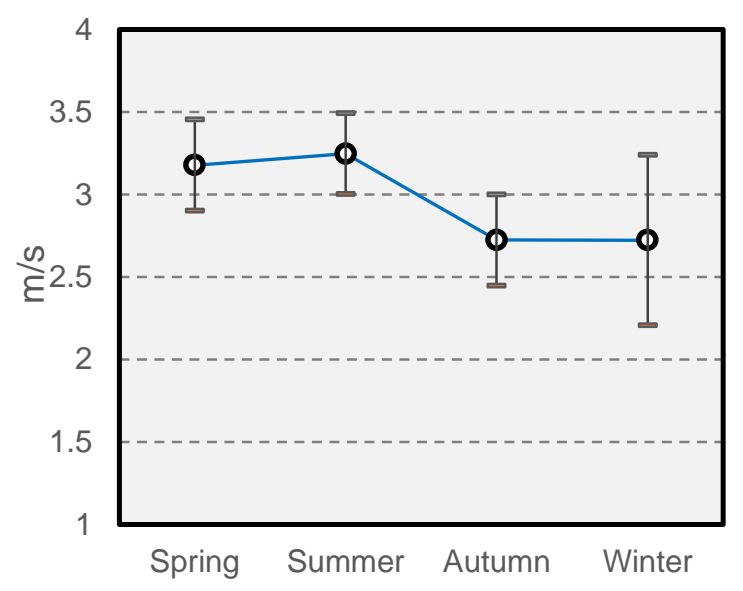

(h) Relative humidity $(\mathrm{H})$

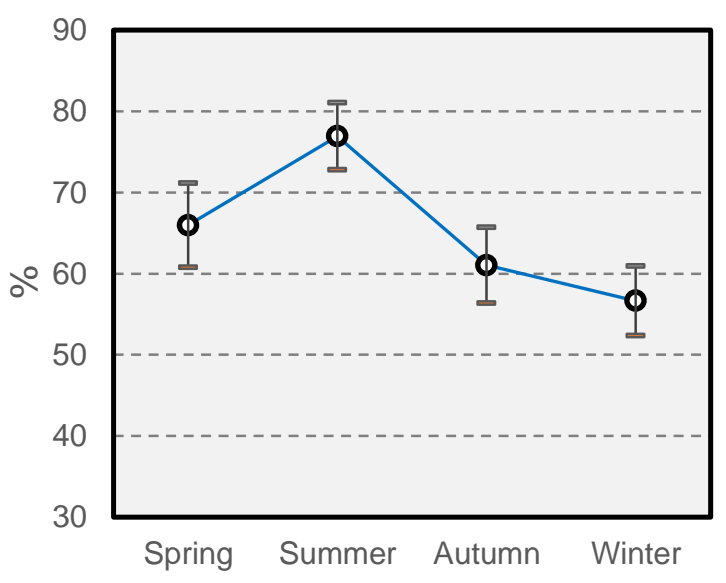

(j) LC mortality

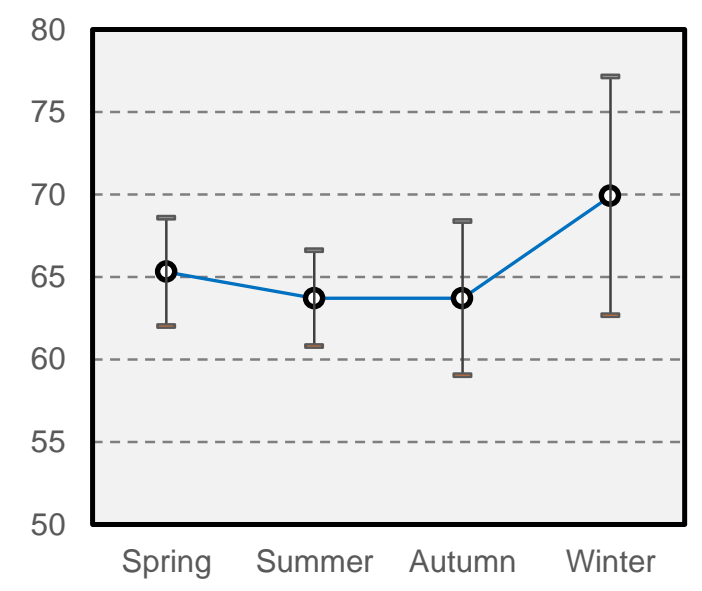

Figure 2. Weekly average values and their $95 \%$ confidence intervals (Cls) of pollutant concentrations (a) $\mathrm{PM}_{2.5}$, (b) $\mathrm{PM}_{10}$, (c) $\mathrm{CO}$, (d) $\mathrm{NO}_{2}$, (e) $\mathrm{SO}_{2}$, (f) $\mathrm{O}_{3}$; meteorological variables (g) temperature, (h) relative humidity, (i) wind speed; and (j) LC mortality in different seasons.

The model fitting in seasonal analyses showed that the associations between air pollutants $\mathrm{PM}_{2.5}, \mathrm{PM}_{10}$ and $\mathrm{NO}_{2}$, and lung cancer mortality with a 3-week lag time were not statistically significant in all the seasons, as showed in Table 5. However, for the effect of meteorological 
changes, it was observed that the individual effect was statistically significant on the relationship between weekly average pollutant concentration and weekly total LC mortality with a 3-week lag during periods of low temperature $\left(T<18^{\circ} \mathrm{C}\right)$, low relative humidity $(H<73.7 \%)$ and low wind speed $(u<2.8 \mathrm{~m} / \mathrm{s})$ recorded, respectively. For each $10 \mu \mathrm{g} / \mathrm{m}^{3}$ increase in weekly average $\mathrm{PM}_{2.5}$, $\mathrm{PM}_{10}$ and $\mathrm{NO}_{2}$ concentration, it was observed that respective increases of $5.9 \%(95 \% \mathrm{Cl}: 2.0 \%$ to $9.9 \%), 4.0 \%(95 \% \mathrm{Cl}: 1.4 \%$ to $6.7 \%)$ and $6.9 \%(95 \% \mathrm{Cl}: 1.5 \%$ to $12.6 \%)$ in weekly total LC mortality cases occurred with a 3-week lag time when the weekly average temperature was less than $18^{\circ} \mathrm{C}$. During periods of low relative humidity $(H<73.7 \%)$, the weekly total $\mathrm{LC}$ mortality with a 3-week lag time increased by $6.3 \%$ (95\% Cl: $-8.4 \%$ to $23.3 \%), 4.1 \%(95 \% \mathrm{Cl}:-8.1 \%$ to $17.8 \%)$ and $4.6 \%$ (95\% Cl: $-10.9 \%$ to $22.7 \%$ ), respectively, for each $10 \mu \mathrm{g} / \mathrm{m}^{3}$ increase in weekly average $\mathrm{PM}_{2.5}, \mathrm{PM}_{10}$ and $\mathrm{NO}_{2}$ concentration. Each $10 \mu \mathrm{g} / \mathrm{m}^{3}$ increase in weekly average $\mathrm{PM}_{2.5}, \mathrm{PM}_{10}$ and $\mathrm{NO}_{2}$ concentration in the period of low wind speed $(u<2.8 \mathrm{~m} / \mathrm{s})$ caused $6.6 \%(95 \% \mathrm{Cl}: 2.1 \%$ to $11.3 \%$ ), $4.0 \%$ (95\% Cl: $1.3 \%$ to $6.9 \%$ ) and $4.8 \%$ (95\% Cl: $0.3 \%$ to $9.6 \%$ ) increases in weekly total LC mortality cases with a 3-week lag time. In contract, it was found there were no statistically significant associations between pollutant concentration and LC mortality during periods of high temperature $\left(T>18^{\circ} \mathrm{C}\right)$, high relative humidity $(H>73.7 \%)$ and high wind speed $(u>2.8 \mathrm{~m} / \mathrm{s})$.

Table 5. Odd ratios (and $95 \mathrm{Cls)}$ of lung cancer (LC) mortality with a 3-week lag time, with respect to each $10 \mu \mathrm{g} / \mathrm{m}^{3}$ increase in single pollutant models $\left(\mathrm{PM}_{2.5}, \mathrm{PM}_{10}, \mathrm{NO}_{2}\right)$ with the effect of seasonal variation and meteorological changes in Ningbo. ( $\left.{ }^{*} \mathrm{P}<0.05\right)$

\begin{tabular}{c|c|c|c}
\hline \multirow{2}{*}{ LC Mortality } & \multicolumn{3}{|c}{ Lag.3w } \\
\cline { 2 - 4 } & $\mathbf{P M}_{2.5}$ & $\mathbf{P M}_{10}$ & $\mathbf{N O}_{2}$ \\
\hline Winter & $1.052(0.980-1.130)$ & $1.038(0.989-1.090)$ & $1.075(0.973-1.189)$ \\
Spring & $1.023(0.862-1.214)$ & $0.984(0.871-1.112)$ & $0.985(0.842-1.152)$
\end{tabular}




\begin{tabular}{|c|c|c|c|}
\hline Summer & $0.920(0.785-1.077)$ & $0.946(0.837-1.070)$ & $0.924(0.757-1.128)$ \\
\hline Autumn & $1.052(0.973-1.137)$ & $1.040(0.989-1.094)$ & $0.996(0.927-1.071)$ \\
\hline$T<18^{\circ} \mathrm{C}$ & $1.059(1.020-1.099)$ * & $1.040(1.014-1.067)$ * & $1.069(1.015-1.126)$ * \\
\hline$T>18^{\circ} \mathrm{C}$ & $1.043(0.982-1.107)$ & $1.039(0.999-1.080)$ * & $1.016(0.950-1.086)$ \\
\hline$H<73.7 \%$ & $1.063(0.916-1.233)$ * & $1.041(0.919-1.178)$ * & $1.046(0.891-1.227)$ * \\
\hline$H>73.7 \%$ & $0.960(0.828-1.114)$ & $0.956(0.845-1.082)$ & $0.942(0.803-1.106)$ \\
\hline$u<2.8 \mathrm{~m} / \mathrm{s}$ & $1.066(1.021-1.113)$ * & $1.040(1.013-1.069)$ * & $1.048(1.003-1.096)$ * \\
\hline$u>2.8 \mathrm{~m} / \mathrm{s}$ & $1.052(0.999-1.109)$ & $1.045(1.006-1.085)$ & $1.029(0.959-1.103)$ \\
\hline
\end{tabular}

\subsection{Stratification analyses by gender and age groups}

When stratified by gender, statistically significant associations were found between both genders (males and females) and LC mortality with a 3-week lag time. An increased risk of lung cancer mortality in the female population demonstrated a strong association with increased $\mathrm{PM}_{2.5}$ and $\mathrm{PM}_{10}$ concentrations, as shown in Table 6 . For the female population, each $10 \mu \mathrm{g} / \mathrm{m}^{3} \mathrm{increase}$ in weekly average $\mathrm{PM}_{2.5}$ and $\mathrm{PM}_{10}$ concentration, the weekly total $\mathrm{LC}$ mortality cases increased by $6.7 \%(95 \% \mathrm{Cl}: 0.6 \%$ to $13.1 \%)$ and $5.0 \%(95 \% \mathrm{Cl}: 1.0 \%$ to $9.1 \%)$ respectively, with a 3-week lag time. Each $10 \mu \mathrm{g} / \mathrm{m}^{3}$ increase in weekly average $\mathrm{PM}_{2.5}$ and $\mathrm{PM}_{10}$ concentration caused the $5.6 \%(95 \% \mathrm{Cl}: 1.8 \%$ to $9.4 \%)$ and $3.5 \%(95 \% \mathrm{Cl}: 1.0 \%$ to $6.0 \%)$ increase of weekly total LC mortality in male population, respectively.

The result also indicated that the effects of $\mathrm{PM}_{2.5}, \mathrm{PM}_{10}$ and $\mathrm{NO}_{2}$ were both statistically significant and stronger in the elderly population, especially in the population aged 50 years or above. For the population aged between 50 and 69 years, the weekly total LC mortality cases 
were increased by $5.6 \%$ (95\% Cl: $0.9 \%$ to $10.6 \%), 5.0 \%$ (95\% Cl: $1.8 \%$ to $8.3 \%)$ and $7.8 \%(95 \%$ $\mathrm{Cl}: 1.9 \%$ to $14.0 \%$ ), with the increase of each $10 \mu \mathrm{g} / \mathrm{m}^{3}$ weekly average $\mathrm{PM}_{2.5}, \mathrm{PM}_{10}$ and $\mathrm{NO}_{2}$ concentration, respectively. Furthermore, the increase of $10 \mu \mathrm{g} / \mathrm{m}^{3}$ weekly average $\mathrm{PM}_{2.5}$ and $\mathrm{PM}_{10}$ concentration caused the increase of $7.0 \%$ (95\% Cl: $2.6 \%$ to $\left.11.6 \%\right)$ and $3.7 \%(95 \% \mathrm{Cl}$ : $0.8 \%$ to $6.6 \%$ ) weekly total LC mortality with a 3-week lag time in the population aged above 69 years. In contrast, no significant association were detected between air pollutant and LC mortality in the younger age group which is below 50 years.

Table 6. Odd ratios (and $95 \mathrm{Cls)} \mathrm{of} \mathrm{lung} \mathrm{cancer} \mathrm{(LC)} \mathrm{mortality} \mathrm{with} \mathrm{a} \mathrm{3-week} \mathrm{lag} \mathrm{time,} \mathrm{with}$ respect to each $10 \mathrm{\mu g} / \mathrm{m}^{3}$ increase in single pollutant models $\left(\mathrm{PM}_{2.5}, \mathrm{PM}_{10}, \mathrm{NO}_{2}\right)$ with different gender and age group in Ningbo. ( $\left.{ }^{*} \mathrm{P}<0.05\right)$

\begin{tabular}{c|c|c|c}
\hline \multirow{2}{*}{ LC Mortality } & \multicolumn{3}{|c}{ Lag.3w } \\
\cline { 2 - 4 } & $\mathbf{P M}_{2.5}$ & $\mathbf{P M}_{10}$ & $\mathbf{N O}_{2}$ \\
\hline Male & $1.056(1.018-1.094) *$ & $1.035(1.010-1.060) *$ & $1.034(0.990-1.079)$ \\
Female & $1.067(1.006-1.131) *$ & $1.050(1.010-1.091) *$ & $1.058(0.986-1.136)$ \\
Age $<50$ & $0.944(0.811-1.099)$ & $0.953(0.861-1.055)$ & $0.926(0.772-1.111)$ \\
Age 50-69 & $1.056(1.009-1.106) *$ & $1.050(1.018-1.083) *$ & $1.078(1.019-1.140) *$ \\
Age > 69 & $1.070(1.026-1.116) *$ & $1.037(1.008-1.066) *$ & $1.020(0.970-1.074)$ \\
\hline
\end{tabular}

\section{Discussion}

In this study, a single pollutant model with Poisson regression was used to study the association between weekly total lung cancer (LC) mortality cases and weekly average pollutant concentrations such as $\mathrm{PM}_{2.5}, \mathrm{PM}_{10}$ and $\mathrm{NO}_{2}$ in Ningbo, China. With the smoothing function in the model fitting, the effect of LC mortality was adjusted for meteorological factors such as wind speed, 
temperature, relative humidity and the effect of week. It was observed that the strongest effects of air pollutants on LC mortality were significant with a lag time of 3 weeks as it resulted in lowest residual errors and AIC values as compared to other models. The risk of weekly total LC mortality with a 3-week lag time was increased by $6.2 \%$ and $4.3 \%$ for each $10 \mu \mathrm{g} / \mathrm{m}^{3}$ increase in weekly average $\mathrm{PM}_{2.5}$ and $\mathrm{PM}_{10}$ concentration, respectively.

Previous studies have shown the important connection between air pollutants and LC mortality. Air pollution exposure has been linked to the generation of reactive oxygen species (ROS) and oxidative damage to DNA that might be associated with the increased risk of lung cancer (Moller et al., 2008). A study using weight-of-evidence approach concluded that exposure to particulate matter may induce direct DNA damage that results in the development of lung cancer (Lynch et al., 2016). To the best of our knowledge, this is the first epidemiological study carried out in China which employs the weekly average pollutant concentrations to evaluate the effect of lag time, meteorological factors and seasonal variation on LC mortality on a weekly basis. Weekly average values of pollutant concentrations were used in this study as the weekly cycle in pollutant concentration was evident in Ningbo. Figure 3(a)-(c) illustrate the weekly cycles of $\mathrm{PM}_{2.5}$, $\mathrm{PM}_{10}$ and $\mathrm{NO}_{2}$, respectively. Behaviours such as the increased usage of motor vehicles and commercial activities, which contribute towards high pollutant concentration levels, occur in urban areas during Fridays and Saturdays. Therefore, by employing the values on weekly basis, the possible confounding effect caused by the weekly cycle in pollutant concentrations can be minimised during the analyses. 
(a)

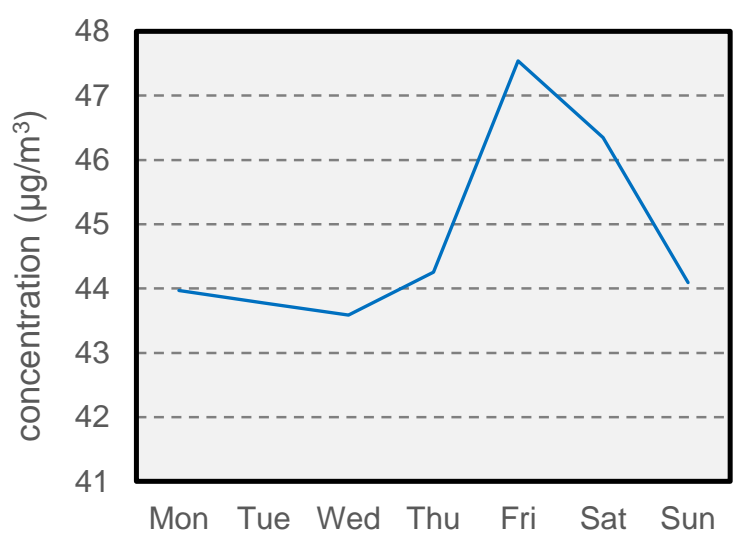

(b)

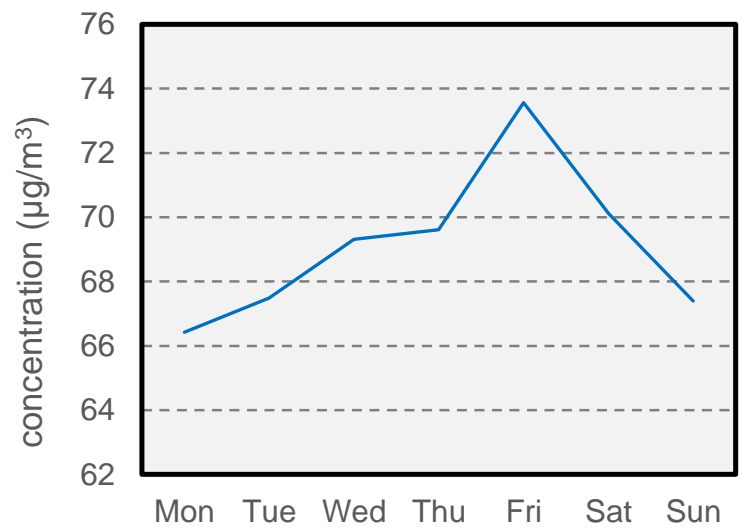

(c)

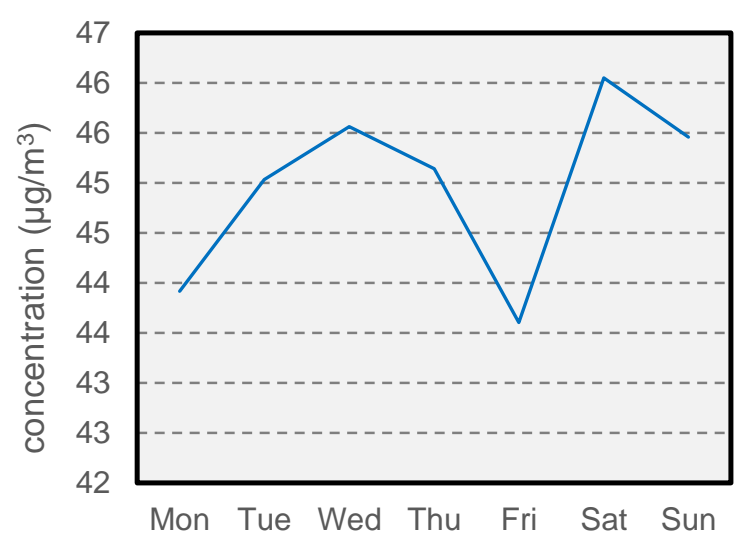

Figure 3. Weekly levels of (a) $\mathrm{PM}_{2.5}$, (b) $\mathrm{PM}_{10}$ and (c) $\mathrm{NO}_{2}$.

In this study, the increase of $6.2 \%$ and $4.3 \%$ weekly total LC mortality cases with a 3-week lag time were associated with an increase per $10 \mu \mathrm{g} / \mathrm{m}^{3}$ weekly average of $\mathrm{PM}_{2.5}$ and $\mathrm{PM}_{10}$, respectively. The current study was compared with the previous studies, suggesting that there are significantly positive associations between exposure to air pollutants and LC mortality, as shown in Table 7. Previous study showed that the effects of $\mathrm{PM}_{2.5}$ and $\mathrm{PM}_{10}$ were much stronger in both Guangzhou and Chongqing during their cold season (Wang et al., 2019). Our result was in line with the findings in the previous study, as similar daily averages of pollutant concentrations can be observed in these cities during their study periods. In periods of low temperature, the effect 
of particulate matter on LC mortality was much greater than periods of high temperature, indicating that there was strong relationship between air pollutant and temperature. Another study conducted in Shenyang concluded that the effects of $\mathrm{PM}_{2.5}$ and $\mathrm{SO}_{2}$ were associated with increased LC mortality levels, especially in the male population, and that exposure to particulate matter could greatly affect the younger population (Xue et al., 2018). Our result showed there is a slightly stronger association between LC mortality and air pollutants in the female population than in the male population, which was different with the previous study (Xue et al., 2018). However, our result was consistent with the findings that female population was found to be more sensitive to exposure to air pollutants than male population (Zhu et al., 2017; Zhu et al., 2019a). A past research conducted in Italy also studied the association between exposure to particulate matter and lung cancer mortality in female population (Uccelli et al., 2016). Another notable result was that exposure to air pollutants significantly affected the elderly population in both age groups of 50-69 years and above 69 years. This is mainly because the efficacy of their immune system levels declines due to aging. Therefore, the elderly population becomes more vulnerable to air pollution-induced health effects (Shumake et al., 2013).

Table 7. Comparison of current study with previous studies conducted in China.

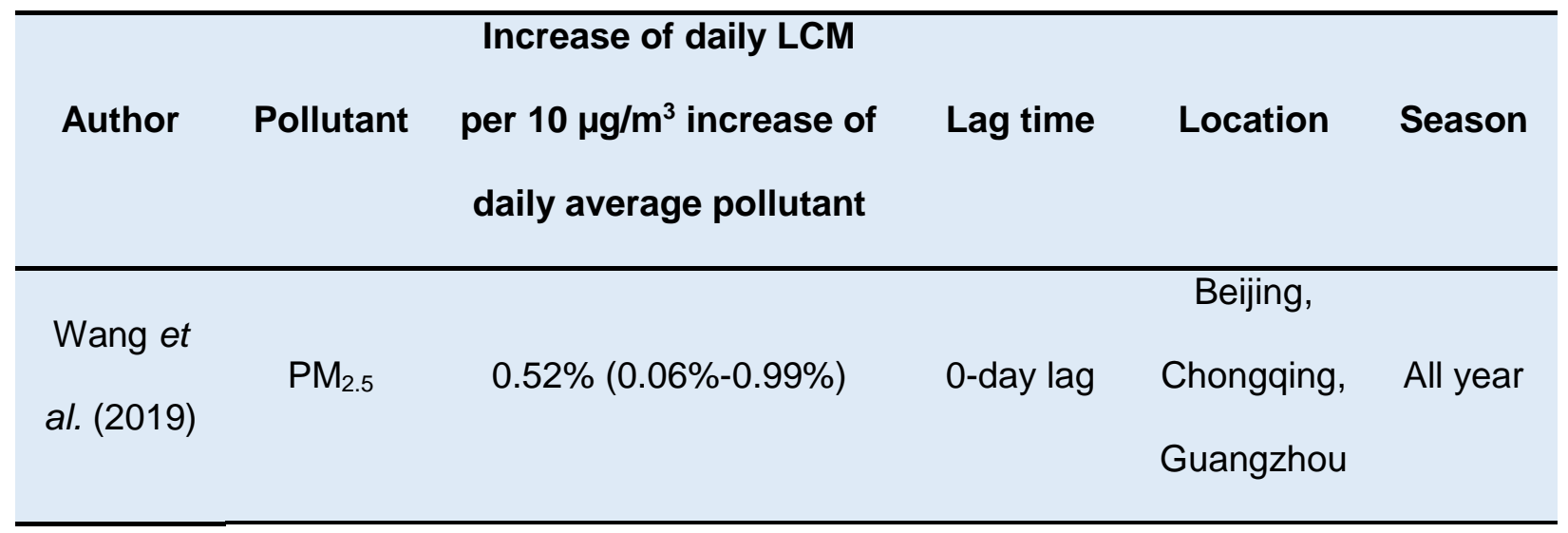




\begin{tabular}{|c|c|c|c|c|c|}
\hline & $\begin{array}{l}\mathrm{PM}_{2.5} \\
\mathrm{PM}_{10}\end{array}$ & $\begin{array}{l}0.94 \%(0.03 \%-1.87 \%) \\
0.99 \%(0.13 \%-1.85 \%)\end{array}$ & 0-day lag & Beijing & $\begin{array}{l}\text { Warm } \\
\text { season }\end{array}$ \\
\hline & $\begin{array}{l}\mathrm{PM}_{2.5} \\
\mathrm{PM}_{10}\end{array}$ & $\begin{array}{l}1.06 \%(0.36 \%-1.76 \%) \\
0.93 \%(0.42 \%-1.45 \%)\end{array}$ & 0-day lag & Chongqing & $\begin{array}{l}\text { Cold } \\
\text { season }\end{array}$ \\
\hline & $\mathrm{PM}_{10}$ & $1.56 \%(0.07 \%-3.06 \%)$ & 0-day lag & Guangzhou & $\begin{array}{c}\text { Cold } \\
\text { season }\end{array}$ \\
\hline $\begin{array}{c}\text { Xue et al. } \\
\text { (2018) }\end{array}$ & $\begin{array}{l}\mathrm{PM}_{2.5} \\
\mathrm{PM}_{10}\end{array}$ & $\begin{array}{l}6.5 \%(1.2 \%-12.0 \%) \\
7.3 \%(0.9 \%-14.0 \%)\end{array}$ & 0-day lag & Shenyang & All year \\
\hline Author & Pollutant & $\begin{array}{l}\text { Increase of weekly LCM } \\
\text { per } 10 \mu \mathrm{g} / \mathrm{m}^{3} \text { increase of } \\
\text { weekly average pollutant }\end{array}$ & Lag time & Location & Season \\
\hline This study & $\begin{array}{l}\mathrm{PM}_{2.5} \\
\mathrm{PM}_{10}\end{array}$ & $\begin{array}{l}6.2 \%(0.2 \%-12.6 \%) \\
4.3 \%(0.1 \%-8.5 \%)\end{array}$ & 3-week lag & Ningbo & All year \\
\hline
\end{tabular}

The seasonal variation of air pollutants was found no statistically significant in this study for $\mathrm{PM}_{2.5}, \mathrm{PM}_{10}$ and $\mathrm{NO}_{2}$, however it demonstrated peak concentrations during the winter and relatively low concentrations during the summer (Figure 1 and Figure 2). The effect of meteorological changes showed statistically significant outcomes for the association between LC mortality with a 3-week lag time and all pollutants $\left(\mathrm{PM}_{2.5}, \mathrm{PM}_{10}\right.$ and $\mathrm{NO}_{2}$, respectively). This may imply that the meteorological variables such as wind speed and relative humidity, which were not consistent within a season, could better explain the relationship between LC mortality and pollutant concentration under different scenarios of meteorological changes. Figure 4 illustrates the profiles of meteorological variables and $\mathrm{PM}_{2.5}$ concentration in Ningbo. From the perspective of meteorological variables, low humidity and low wind speed levels may contribute towards a poor dispersion environment for pollutants. Therefore, the air pollutants tend to disperse slowly 
and stay for a longer time in the region, which increase the exposure time for its residents. The combined effects of low humidity and low wind speed may potentially exacerbate the influence of air pollutants on LC mortality, especially in winter and autumn where their temperatures are even lower. As shown in Table 5, this study reported that the association between air pollutants and LC mortality was stronger during periods of low temperature, low relative humidity and low wind speed respectively.

(a)

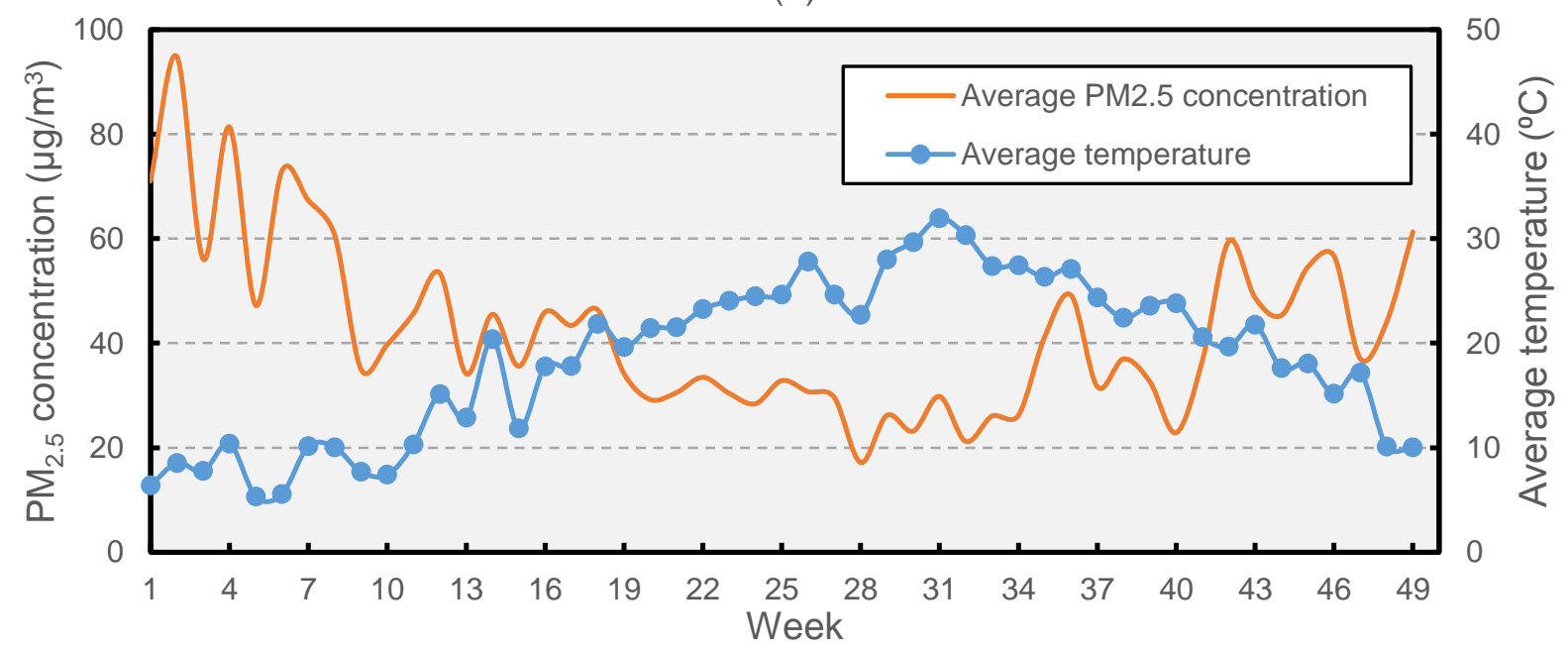

(b)

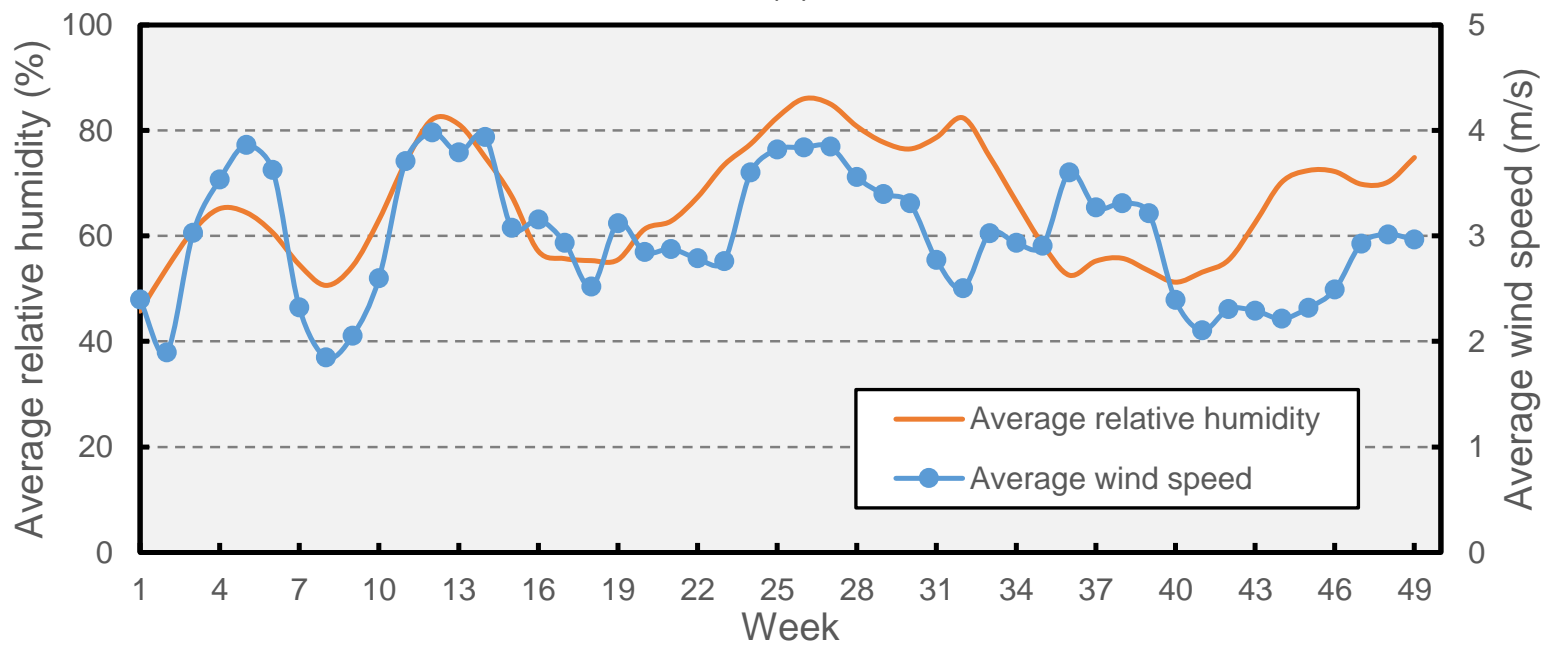

Figure 4. Profiles of (a) $\mathrm{PM}_{2.5}$ concentration and temperature; (b) Relative humidity and wind speed in Ningbo in 2015. 
Conversely, it was noted that the number of LC mortality cases did not reduce in summer when the pollutant concentrations for $\mathrm{PM}_{2.5}, \mathrm{PM}_{10}$ and $\mathrm{NO}_{2}$ were significantly decreased. The average pollutant concentrations were below the IAQI values of 50 , which implies almost no significant impact of $\mathrm{PM}_{2.5}, \mathrm{PM}_{10}$ and $\mathrm{NO}_{2}$ on $\mathrm{LC}$ mortality during summer. This may be linked to the effect of $\mathrm{O}_{3}$, which generally has a relatively higher concentration in summer due to the higher temperatures and increased amount of sunlight enhancing the production of $\mathrm{O}_{3}$ (Wang et al., 2017). A positive correlation was also observed between $\mathrm{O}_{3}$ and temperature, as shown in Table 3. Ozone is a secondary pollutant and its actual mechanism for affecting human health remains inconclusive. Future works will be required to investigate the individual effect of $\mathrm{O}_{3}$ on the $\mathrm{LC}$ mortality, especially during the summer period.

Our model has evidently showed the association between air pollutants $\left(\mathrm{PM}_{2.5}, \mathrm{PM}_{10}\right.$ and $\mathrm{NO}_{2}$ ) and LC mortality with the effect of lag time on a weekly basis. Our result may provide some insights into the possible mechanism of air pollutant exacerbating the health condition of a lung cancer patient, which is related to weekly variation of pollutant. Therefore, in order to minimise the impact of air pollution on health burden of the local population, it requires intermediate actions for the air quality improvement such as implementation of stringent regulations and appropriate measure of controlling the pollution from road transport sector especially in urban areas (Angelevska et al., 2021). The introduction of advanced technologies for pollutant removal also plays an important role in air pollution control such as an improved design of catalytic converter for ozone removal (Wu et al., 2019).

The current study has some limitations, as well as recommendation of future works. Firstly, pollutant data and meteorological data were only obtained from two monitoring stations to 
represent the actual exposure of the study population, which might lead to measurement errors. Spatial modelling is recommended to estimate the dispersion of pollutant across the city and to improve the accuracy in predicting the impact of air pollutants on LC mortality. Secondly, the effects of indoor air pollution and the smoking habit of patients were not considered due to a lack of relevant data. Previous study showed that the respiratory symptoms and impaired lung functions in female population was linked to higher level of indoor air pollution (Mulenga and Siziya, 2019). It might be a potential confounding factor of the stronger association between LC mortality in female population and air pollutant in this study. Thirdly, a study of lung cancer morbidity was not included, which may underestimate the actual association of air pollution and lung cancer disease. It is suggested that future works employ hospital admission data related to respiratory diseases such as asthma and pneumonia when assessing the impact of air pollutionassociated health effects. Finally, the analysis was only performed on Ningbo in 2015 as a case study. Different locations and more study periods should ideally be explored and analysed in order to improve the generalisability of this study.

\section{Conclusions}

In summary, by using Ningbo as a case study to represent the Yangtze River Delta region, this study has demonstrated and concluded with some important findings below:

(1) It has found statistically significant associations between air pollutants $\left(\mathrm{PM}_{2.5}\right.$ and $\left.\mathrm{PM}_{10}\right)$ and lung cancer mortality with a 3-week lag time.

(2) It was observed that high pollutant concentrations were generally found during the winter season, conversely, relatively low pollutant concentrations were found during the summer season. 
(3) This study has provided further evidence on the statistically significant association between lung cancer mortality and air pollution during periods of low temperature, low humidity and low wind speed.

(4) The effect of air pollutants on lung cancer mortality was slightly stronger in female population than in male population.

(5) It was observed that the elderly population was more susceptible to exposure to air pollutants, especially those aged 50 years or above with the exposure to particulate matter $\left(\mathrm{PM}_{2.5}\right.$ and $\left.\mathrm{PM}_{10}\right)$. It is suggested that more attentions should be given to elderly population and lung cancer patients especially during cold season with low humidity and low wind speed. In addition, more specific mitigation measures against ambient air pollution in terms of advanced technologies and stringent regulations should be introduced and implemented in order to greatly reduce the impact of air pollution on the health burden in China.

\section{Acknowledgements}

This study was financially supported by the National Natural Science Foundation of China (Grant no. 21750110446). The authors would like to thank Ningbo Environmental Monitoring Centre (Ningbo EMC) and Ningbo Centre for Disease Control and Prevention (Ningbo CDC) for sharing the data. Chung C. Y. was supported by the Faculty of Science and Engineering PhD scholarship (Ref No. 19073FOSE) at University of Nottingham Ningbo China (UNNC). 


\section{Abbreviations}

$\begin{array}{ll}\text { AIC } & \text { Akaike information criterion } \\ \text { AQI } & \text { Air Quality Index } \\ \mathrm{CO} & \text { Confidence interval } \\ \mathrm{GDP} & \text { Carbon monoxide } \\ \mathrm{IAQI} & \text { Gross domestic product } \\ \mathrm{LC} & \text { Individual Air Quality Index } \\ \mathrm{LCM} & \text { Lung cancer } \\ \mathrm{NO}_{2} & \text { Nitrogen dioxide } \\ \mathrm{O}_{3} & \text { Ozone } \\ \mathrm{PM}_{\mathrm{PM}} & \text { Particle matter } \\ \mathrm{PM}_{2.5} & \text { Particles with an aerodynamic diameter of less than } 2.5 \mu \mathrm{m} \\ \mathrm{PM}_{10} & \text { Particles with an aerodynamic diameter of less than } 10 \mu \mathrm{m} \\ \mathrm{RMSE}_{\mathrm{SD}} & \text { Root mean square error } \\ \mathrm{SO}_{2} & \text { Standard deviation } \\ \end{array}$

\section{References}

Alberg, A. J. \& Samet, J. M. (2003). Epidemiology of lung cancer*. Chest, 123(1), 21S-49S.

Angelevska, B., Atanasova, V. \& Andreevski, I. (2021). Urban air quality guidance based on measures categorization in road transport. Civil Engineering Journal, 7(2), 253-267. 
Apte, J., Marshall, J., Cohen, A. \& Brauer, M. (2015). Addressing global mortality from ambient PM2.5. Environmental Science \& Technology, 49(13), 8057-8066.

Brunekreef, B. \& Holgate, S. T. (2002). Air pollution and health. The Lancet, 360(9341), 12331242.

Burnett, R., Pope, C., Ezzati, M., Lim, S., Mehta, S., Shin, H., et al. (2014). An integrated risk function for estimating the global burden of disease attributable to ambient fine particulate matter exposure. Environmental Health Perspect, 122(4), 397-403.

Chen, R., Peng, R. D., Meng, X., Zhou, Z., Chen, B. \& Kan, H. (2013). Seasonal variation in the acute effect of particulate air pollution on mortality in the China Air Pollution and Health Effects Study (CAPES). Science of the Total Environment, 450-451, 259-265.

Chen, W., Wang, F., Xiao, G., Wu, K. \& Zhang, S. (2015). Air quality of Beijing and impacts of the new ambient air quality standard. Atmosphere, 6(8), 1243-1258.

Chen, W. \& Xu, R. (2010). Clean coal technology development in China. Energy Policy, 38(5), 2123-2130.

Fitzmaurice, C., Global Burden of Disease Cancer, C., Allen, C., Barber, R. M., Barregard, L., Bhutta, Z. A., et al. (2017). Global, regional, and national cancer incidence, mortality, years of life lost, years lived with disability, and disability-adjusted life-years for 32 cancer groups, 1990 to 2015: a systematic analysis for the Global Burden of Disease study. JAMA Oncology, 3(4), 524548.

Forouzanfar, M. H., Afshin, A., Alexander, L. T., Anderson, H. R., Bhutta, Z. A., Biryukov, S., et al. (2016). Global, regional, and national comparative risk assessment of 79 behavioural, 
environmental and occupational, and metabolic risks or clusters of risks, 1990-2015: a systematic analysis for the Global Burden of Disease Study 2015. The Lancet, 388(10053), 1659-1724.

Guo, Y., Barnett, A., Pan, X., Yu, W. \& Tong, S. (2011). The impact of temperature on mortality in Tianjin, China: A case-crossover design with a distributed lag nonlinear model. Environmental Health Perspectives, 119(12), 1719-1725.

Huang, J., Pan, X., Guo, X. \& Li, G. (2018). Health impact of China's Air Pollution Prevention and Control Action Plan: an analysis of national air quality monitoring and mortality data. The Lancet Planetary Health, 2(7), e313-e23.

Jiang, Y., Niu, Y., Xia, Y., Liu, C., Lin, Z., Wang, W., et al. (2019). Effects of personal nitrogen dioxide exposure on airway inflammation and lung function. Environmental Research, 177, 108620.

Jin, L., Luo, X., Fu, P. \& Li, X. (2016). Airborne particulate matter pollution in urban China: A chemical mixture perspective from sources to impacts. National Science Review, 4, 593-610.

Limaye, V., Schöpp, W. \& Amann, M. (2018). Applying integrated exposure-response functions to PM2.5 pollution in India. International Journal of Environmental Research and Public Health, 16(1), 60.

Li, Y., Chen, Q., Zhao, H., Wang, L. \& Tao, R. (2015). Variations in PM10, PM2.5 and PM1.0 in an urban area of the Sichuan Basin and their relation to meteorological factors. Atmosphere, 6(1), 150-163.

Lynch, H. N., Loftus, C. T., Cohen, J. M., Kerper, L. E., Kennedy, E. M. \& Goodman, J. E. (2016). Weight-of-evidence evaluation of associations between particulate matter exposure and biomarkers of lung cancer. Regulatory Toxicology and Pharmacology, 82, 53-93. 
Moller, P., Folkmann, J. K., Forchhammer, L., Brauner, E. V., Danielsen, P. H., Risom, L. et al. (2008). Air pollution, oxidative damage to DNA, and carcinogenesis. Cancer Letters, 266(1), 8497.

Mulenga, D. and Siziya, S. (2019). Indoor air pollution related respiratory ill health, a sequel of biomass use. SciMedicine Journal, 1(1), 30-37

Oo, H., Zin, W. \& Thin Kyi, C. (2020). Analysis of streamflow response to changing climate conditions using SWAT model. Civil Engineering Journal, 6(2), 194-209.

Peng, R. D., Dominici, F., Pastor-Barriuso, R., Zeger, S. L. \& Samet, J. M. (2005). Seasonal analyses of air pollution and mortality in 100 US cities. American Journal of Epidemiology, 161(6), 585-594.

Pope, C. A., 3rd, Burnett, R. T., Turner, M. C., Cohen, A., Krewski, D., Jerrett, M., et al. (2011). Lung cancer and cardiovascular disease mortality associated with ambient air pollution and cigarette smoke: shape of the exposure-response relationships. Environmental Health Perspectives, 119(11), 1616-1621.

Qiu, H., Yu, H., Wang, L., Zhu, X., Chen, M., Zhou, L., et al. (2018). The burden of overall and cause-specific respiratory morbidity due to ambient air pollution in Sichuan Basin, China: A multicity time-series analysis. Environmental Research, 167, 428-436.

Rohde, R. \& Muller, R. (2015). Air pollution in china: mapping of concentrations and sources. PLOS ONE, 10(8), e0135749.

Shumake, K. L., Sacks, J. D., Lee, J. S. \& Johns, D. O. (2013). Susceptibility of older adults to health effects induced by ambient air pollutants regulated by the European Union and the United States. Aging Clin Exp Res, 25(1), 3-8. 
Tang, Y.-T., Chan, F. K. S. \& Griffiths, J. (2015). City profile: Ningbo. Cities, 42, 97-108.

Tanoue, L. (2012). Lung Cancer. Clinical Respiratory Medicine, 788-800.

Uccelli, R., Mastrantonio, M., Altavista, P., Caiaffa, E., Cattani, G., Belli, S., et al. (2017). Female lung cancer mortality and long-term exposure to particulate matter in Italy. European Journal of Public Health, 27(1), 178-183.

Wang, N., Mengersen, K., Tong, S., Kimlin, M., Zhou, M., Wang, L., et al. (2019). Short-term association between ambient air pollution and lung cancer mortality. Environmental Research, 179, 108748.

Wang, W. N., Cheng, T. H., Gu, X. F., Chen, H., Guo, H., Wang, Y., et al. (2017). Assessing spatial and temporal patterns of observed ground-level ozone in China. Scientic Reports, $7(1)$, 3651.

Wu, F., Lu, Y., Wang, M., Zhang, X. \& Yang, C. (2019). Catalytic removal of ozone by Pd/ACFs and optimal design of ozone converter for air purification in aircraft cabin. Civil Engineering Journal, 5(8), 1656-1671.

Xue, X., Chen, J., Sun, B., Zhou, B. \& Li, X. (2018). Temporal trends in respiratory mortality and short-term effects of air pollutants in Shenyang, China. Environmental Science and Pollution Research, 25(12), 11468-11479.

Yang, G., Wang, Y., Zeng, Y., Gao, G. F., Liang, X., Zhou, M., et al. (2013). Rapid health transition in China, 1990-2010: findings from the Global Burden of Disease Study 2010. The Lancet, 381(9882), 1987-2015. 
You, M. (2014). Addition of PM 2.5 into the national ambient air quality standards of China and the contribution to air pollution control: the case study of Wuhan, China. Scientific World Journal, 2014, 768405.

Zhu, F., Ding, R., Lei, R., Cheng, H., Liu, J., Shen, C., et al. (2019a). The short-term effects of air pollution on respiratory diseases and lung cancer mortality in Hefei: A time-series analysis. Respiratory Medicine, 146, 57-65.

Zhu, J., Zhang, X., Zhang, X., Dong, M., Wu, J., Dong, Y., et al. (2017). The burden of ambient air pollution on years of life lost in Wuxi, China, 2012-2015: A time-series study using a distributed lag non-linear model. Environmental Pollution, 224, 689-697.

Zhu, X., Qiu, H., Wang, L., Duan, Z., Yu, H., Deng, R., et al. (2019b). Risks of hospital admissions from a spectrum of causes associated with particulate matter pollution. Science of The Total Environment, 656, 90-100. 